\title{
Factor V Leiden homozygous mutation: Recurrent venous thromboembolism during periods of discontinuation of anticoagulant therapy
}

\author{
Sabira Šahinović ${ }^{,}$Vildana Huskićc ${ }^{*}$, Adis Kauković \\ ${ }^{1}$ Department of Emergency Medicine, Community Health Centre Bužim, Bosnia and Herzegovina, '2Department of Family Medicine, \\ Community Health Centre Bužim, Bosnia and Herzegovina
}

\begin{abstract}
Venous thromboembolism (VTE), also known as deep vein thrombosis and pulmonary thromboembolism, is a medical condition that has a high incidence and a multifactorial pathogenesis. One of the causes is a mutation of the Factor $V$ Leiden (FVL), which is the most common inherited thrombotic disorder. A mutation inherited from both parents is found in about $0.05-0.5 \%$ of cases, making our case more medically interesting. We presented the case of a young male patient with recurrent VTE and few risk factors who was admitted to the hospital 4 times with VTE symptoms over a 5-year period. In the background, there was a homozygous FVL mutation and improper use of anticoagulant therapy. We examined the medical data, diagnostics, therapy, and precautions that were and are required.
\end{abstract}

KEYWORDS: Venous thromboembolism; homozygous Factor $V$ Leiden mutation; anticoagulant therapy

\section{INTRODUCTION}

Venous thromboembolism (VTE) is a common medical condition that can lead to potentially fatal complications if not recognized and treated promptly and effectively. It is comprised two distinct clinical entities: Deep vein thrombosis (DVT) and pulmonary thromboembolism (PTE). VTE pathogenesis is multifactorial and frequently reflects the interaction of environmental, clinical, and genetic factors (1).

A point mutation in the Factor V Leiden (FVL) gene was first described in 1994, when arginine 506 was replaced by glutamine. The resulting mutated factor $\mathrm{V}$ exhibits normal procoagulant activity but is less sensitive to activated protein C (APC). The paucity of APC proteolytic activity causes hypercoagulability, which carries the potential of thrombosis (2-4). It was subsequently shown that this mutation is associated with $18-20 \%$ of all idiopathic cases of VTE $(5,6)$.

The most common inherited thrombotic disorder is the FVL mutation. It is estimated that approximately $5 \%$ of the European population is a carrier of the FVL mutation from one parent (heterozygotes) (7). Approximately 0.05-0.5\% of cases, the disease is inherited from both parents (8). Risk factors such as older age, smoking, surgery, obesity,

*Corresponding author: Vildana Huskić, Department of Emergency Medicine, Community Health Centre, Generala Izeta Nanića 36,77 245 Bužim, Bosnia and Herzegovina, Tel: +387 61815 863, E-mail: wildana_ huskic@hotmail.com

Submitted: 10 March 2021/Accepted: 07 July 2021

DOI: https://doi.org/10.17532/jhsci.2021.1283 immobility, prolonged travel, hospitalization, oral contraceptive use, hormonal replacement therapy, pregnancy, and malignancy all increase the risk of VTE in healthy people as well as those with the FVL mutation (7).

This case report describes a case of VTE in a younger male patient (with FVL homozygote mutation) with a few risk factors, in which DVT developed on numerous occasions and was regularly complicated by PTE. Consequently, we examined the diagnostics, therapy, and precautions that were and are considered necessary.

\section{CASE REPORT}

A 24-year-old male patient (presented to the emergency room in May 2016) complained of left leg pain and swelling, left-sided chest pain, breathing difficulties, and coughing up fresh blood. He was a car mechanic, a smoker, and he actively consumed alcohol. He was previously treated for a mild form of psoriasis and has been in remission for many years. At the age of 60 , both his parents endured an ischemic stroke. He was taken to a local hospital and then to the Clinical Center of the University of Sarajevo, under the diagnosis of DVT of the left leg and suspected PTE.

\section{$1^{\text {st }}$ hospitalization (May 2016)}

At the admission, the body temperature was $37.1^{\circ} \mathrm{C}$, the blood pressure was $140 / 90 \mathrm{mmHg}$, the oxygen saturation was $93 \%$, and the ECG showed sinus tachycardia (112/min) with no signs of acute coronary pathology. Other laboratory 
parameters were normal, except an increased erythrocyte sedimentation rate of $87 \mathrm{~mm} / \mathrm{h}$ and C-reactive protein (CRP) of $124 \mathrm{mg} / \mathrm{L}$. Acid-base status also showed no signs of respiratory insufficiency. The D-dimer was not mentioned in the release summary. Chest X-ray revealed a raised left hemidiaphragm and intense homogeneous shading at the base of the left lung, with a flat upper border (Figure 1). A thrombosis of the left femoral vein was indicated by a color Doppler of blood vessels. Chest computed tomography $(\mathrm{CT})$ revealed evidence of extensive bilateral PTE, including extensive pulmonary infarction in the lower left lung lobe, minor pulmonary infarction in the middle lung lobe, and minor left pleural effusion (Figures 2 and 3).

Anticoagulant therapy with low-molecular-weight heparin was introduced, later switched to oral therapy. Clinical and subjective recovery occurred with additional antibiotic and analgesic therapy. At discharge, an X-ray of the lungs revealed a complete regression of the described changes. After 19 days of hospitalization in intensive care unit and semi-intensive care unit, he was discharged for home treatment with acenocoumarol therapy, with INR 3.0 at discharge. A test for thrombophilia was done, but by the time of discharge, the results had not arrived. Shortly afterward, the patient stopped taking the mentioned therapy on his own and having regular check-ups. The results of the molecular test were never available.

\section{$2^{\text {nd }}$ hospitalization (July 2018)}

The patient was referred to the hospital for the left lower leg redness and swelling, as well as chest pain and coughing up a small amount of fresh blood. An X-ray of the lungs revealed no significant radiographic changes (Figure 4). Due to low values of D-dimer $(0.3 \mathrm{ug} / \mathrm{mL}$ FEU, reference range up to $0.5 \mathrm{ug} / \mathrm{mL}$ FEU) with the regression of symptoms and the supervision of a vascular surgeon, the patient was discharged for home treatment after 11 days. A chest CT was not performed. Topical treatment (heparin sodium $1000 \mathrm{I}$.U/g ointment) relieved local symptoms of thrombophlebitis. Other laboratory findings, except CRP $14 \mathrm{mg} / \mathrm{L}$, were within the normal range.

\section{$3^{\text {th }}$ hospitalization (January 2020)}

The patient was admitted to the cardiology department due to pain along the entire left leg, redness in the left lower leg, and right-sided chest pain with coughing up a small amount of fresh blood. He was afebrile, eupneic at rest, and had a blood pressure of 130/80 mmHg. ECG showed sinus tachycardia 113/min and S1Q3T3 pattern. A chest X-ray showed a shadow of pneumonic infiltration at the level of the right hilus caudal unfolding (Figures 5 and 6).

Chest CT angiography revealed a linear zone of altered density - thrombus in the right pulmonary artery and the segmental artery for the posterobasal segment of the lower lobe, as well as signs of pulmonary infarction and minor pleura effusion (Figure 7).

Ultrasound of the lower extremities showed DVT from the level of the posterior tibial veins of the left leg, the left popliteal vein, the left femoral vein, thrombosis of the left saphenofemoral orifice, and the entire length of the great superficial saphenous vein and its tributaries. There was also visible thrombosis of the left common femoral vein and the

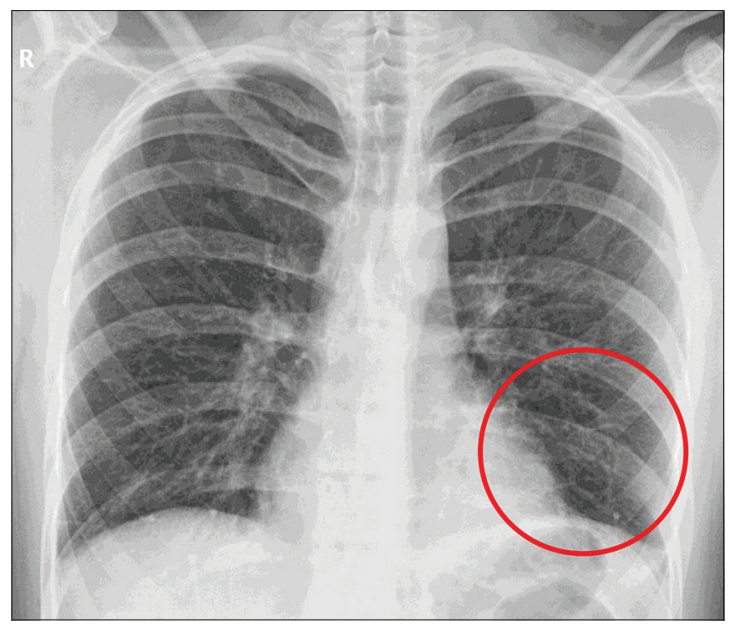

FIGURE 1. Chest X-ray - May 16, 2016.

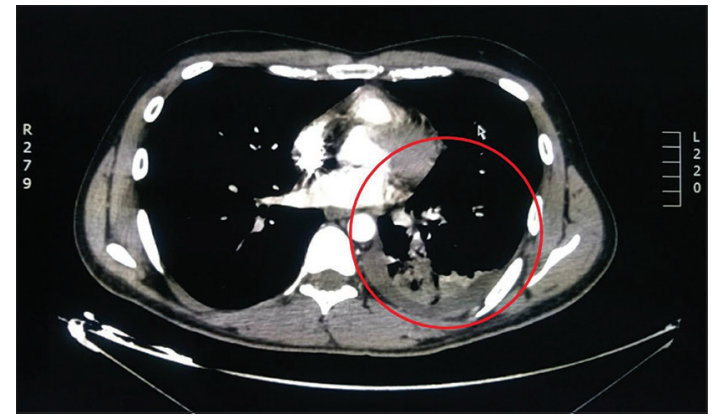

FIGURE 2. Chest CT - May 16, 2016.

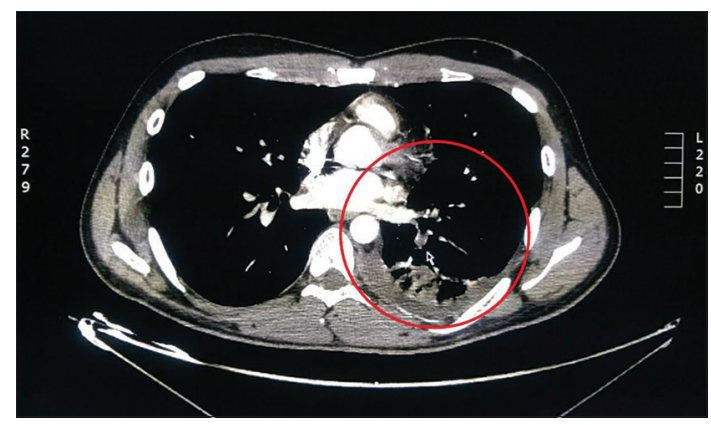

FIGURE 3. Chest CT - May 16, 2016. 2. Cross-section.

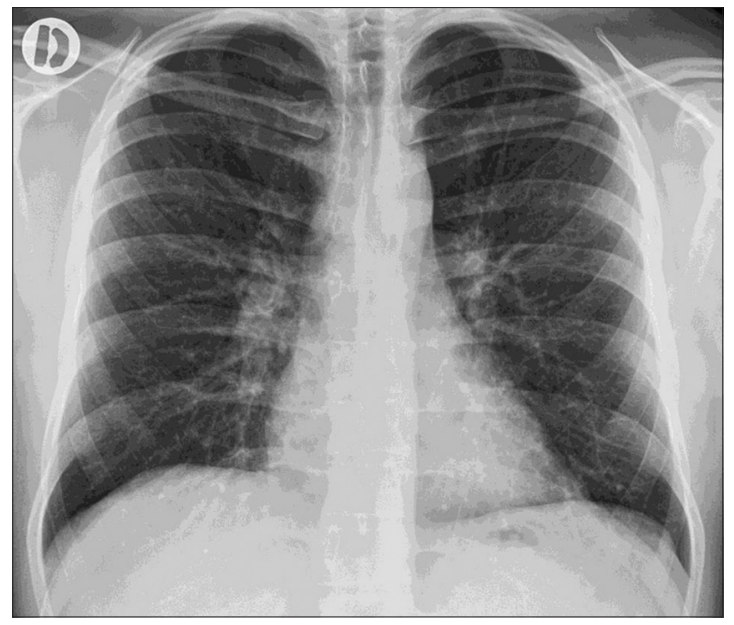

FIGURE 4. Chest X-ray - July 9, 2018.

left external iliac vein until it connects with the left common iliac vein. On the right leg, there was no evidence of deep venous thrombosis, but there was evidence of chronic 
venous insufficiency. On both, lower legs were signs of superficial thrombophlebitis.

Echocardiography: Normal findings. Laboratory findings were within reference range, except CRP $(33.9 \mathrm{mg} / \mathrm{L}$ on admission, $286.6 \mathrm{mg} / \mathrm{L}$ during hospitalization, and $27.4 \mathrm{mg} / \mathrm{L}$ at discharge) and electrolyte disturbances $\mathrm{Na}^{+}$ 129.9 (136-145 mmol/l) and $\mathrm{Cl}^{-} 95.9$ (101-111 $\left.\mathrm{mmol} / \mathrm{L}\right)$ during hospitalization.

After 18 days of hospitalization with low-molecular-weight heparin, antibiotics, and analgesics, the patient was discharged to home treatment with an anticoagulant therapy recommendation (rivaroxaban $2 \times 15 \mathrm{mg}$, then $1 \times 20 \mathrm{mg}$ ). Again, a molecular test for thrombophilia was required, which could

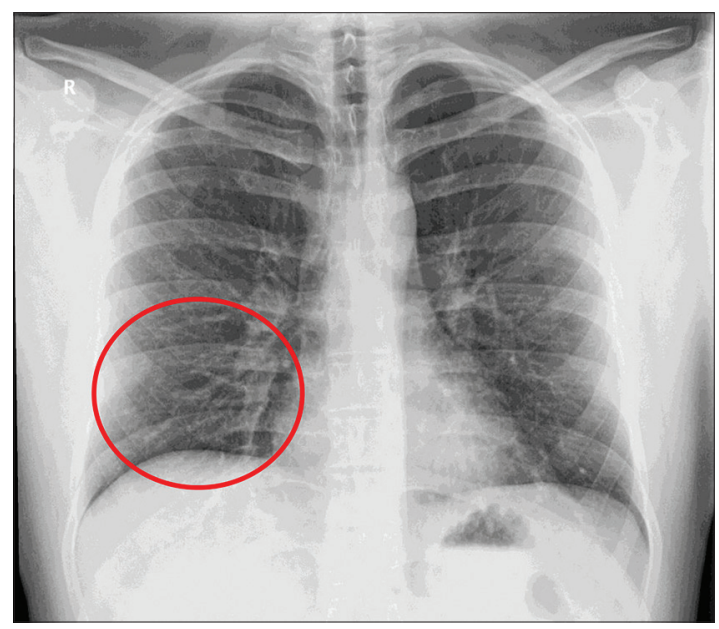

FIGURE 5. Chest X-ray - January 27, 2020.

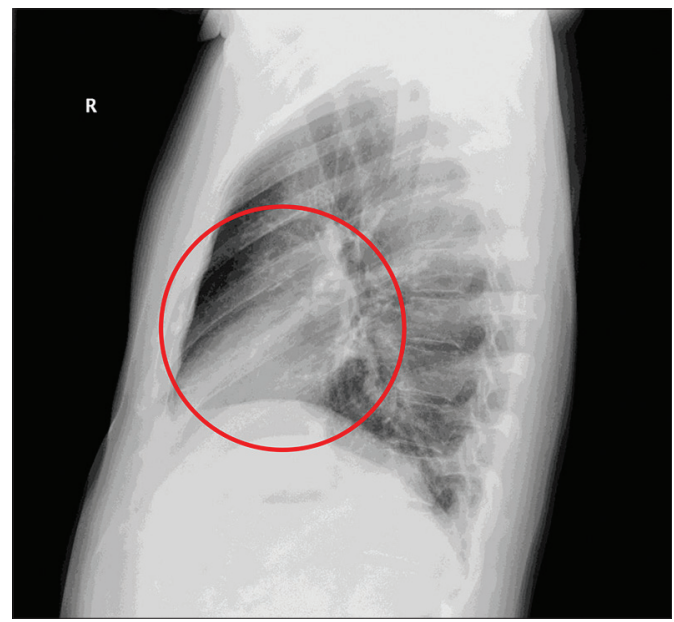

FIGURE 6. Chest X-ray - January 27, 2020 - left profile.



FIGURE 7. Chest CT angiography - January 29, 2020. not be performed until December 2020 due to the COVID19 pandemic. The patient's blood was taken in one of the outpatient appointments and sent to the laboratory. The patient did not take any anticoagulant medication in this period.

\section{$4^{\text {th }}$ hospitalization (January 2021)}

At admission, he complained of dyspnea, right-sided chest pain, and blood in the sputum, but not of pain or swelling in the lower extremities. Laboratory findings at admission are presented in Table 1. PTE was rediagnosed following another self-initiated discontinuation of anticoagulant therapy.

Chest X-ray showed a right basal infra and perihilar visible one-banded shadow, most likely corresponding to plate-like atelectasis (Figure 8). Chest CT angiography showed the presence of a thrombus in the segmental artery of the lower right lobe's posterobasal segment of the lungs (Figure 9). ECG and echocardiography showed no significant changes.

The patient responded well to anticoagulant therapy and was discharged after 14 days for home treatment with anticoagulant therapy (rivaroxaban $2 \times 15 \mathrm{mg}$ ).

Upon being discharged from the hospital in January 2021, molecular tests indicated a homozygous mutation $\mathrm{F} V$ (Leiden): FV506 (genotype AA)/carrier of the homozygous mutation. Genotyping of the F II gene did not reveal the presence of a mutation: F II20210/genotype GG.

Other required tests showed normal results: Antithrombin III, protein $C$, and protein $S$ were all within the normal range. Antinuclear antibodies, lupus anticoagulant (LA1,

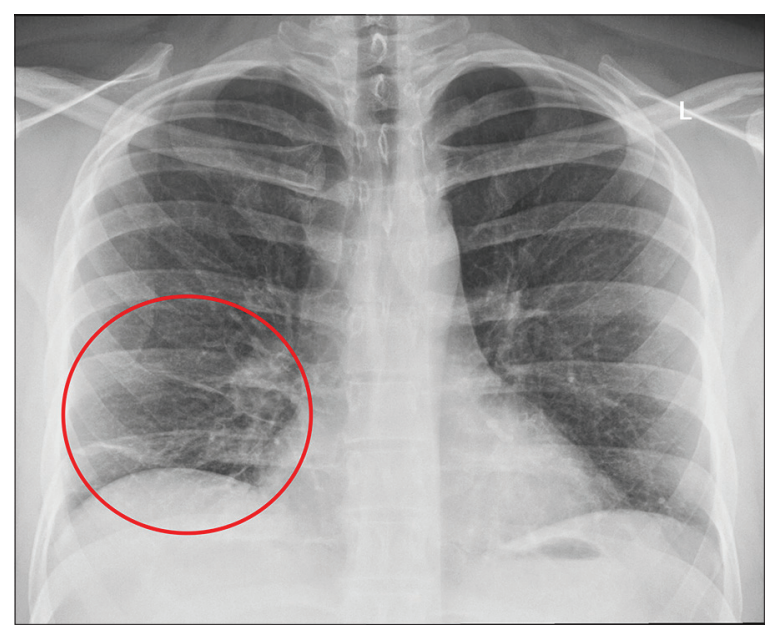

FIGURE 8. Chest X-ray - January 5, 2021.

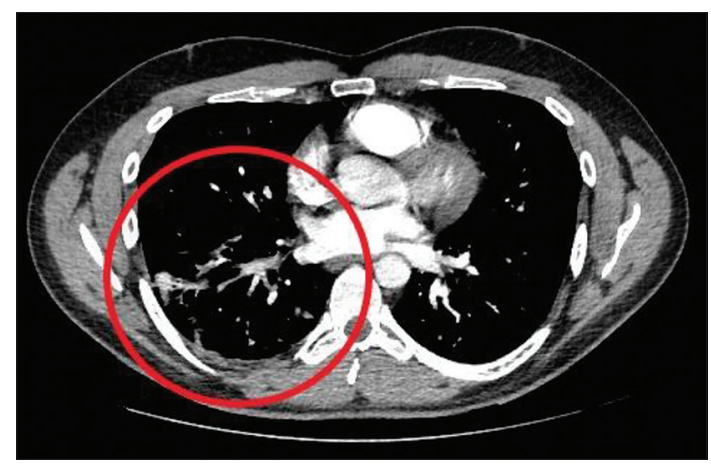

FIGURE 9. Chest CT angiography - January 7, 2021. 
TABLE 1. Laboratory findings at admission, January 2021

\begin{tabular}{lcc}
\hline Parameter & Reference range & On admission \\
\hline CRP & Up to $3.3 \mathrm{mg} / \mathrm{L}$ & 5.2 \\
Blood glucose & $3.9-6.1 \mathrm{mmol} / \mathrm{L}$ & 6.7 \\
Urea & $2.5-6.4 \mathrm{mmol} / \mathrm{L}$ & 4.8 \\
Creatinine & $53-115 \mathrm{umol} / \mathrm{L}$ & 83 \\
Total bilirubin & $1.7-20.5 \mathrm{umol} / \mathrm{L}$ & 11.4 \\
LDH & $125-243 \mathrm{U} / \mathrm{L}$ & 187 \\
AST & $15-37 \mathrm{U} / \mathrm{L}$ & 33 \\
ALT & $30-65 \mathrm{U} / \mathrm{L}$ & 119 \\
Na + & $136-145 \mathrm{mmol} / \mathrm{L}$ & 141 \\
K+ & $3.5-5.1 \mathrm{mmol} / \mathrm{L}$ & 3.8 \\
Cl- & $101-111 \mathrm{mmol} / \mathrm{L}$ & 102 \\
CK & $30-200 \mathrm{U} / \mathrm{L}$ & 70 \\
CK-MB & $<24 \mathrm{U} / \mathrm{L}$ & 14 \\
HS-Troponin & $<34.2 \mathrm{pg} / \mathrm{mL}$ & 0.0 \\
INR & $0.7-1.1$ & 0.85 \\
D-dimer & $<0.5 \mathrm{mg} / \mathrm{ml}$ & 0.6 \\
APTV-s & $23-36 \mathrm{~s}$ & 25.4 \\
Complete blood count & & \\
Leukocytes & $3.4-9.7$ & 7.3 \\
Erythrocytes & $4.34-5.72$ & 5.27 \\
Hemoglobin & $8.60-10.90$ & 10.13 \\
Hematocrit & $0.41-0.53$ & 0.45 \\
MCV & $83-97.2 f l$ & 85.6 \\
Thrombocytes & $158-424$ & 196 \\
\hline & &
\end{tabular}

LA2, and LA ratio), anti-cyclic citrullinated peptide $\operatorname{IgG}$ (CCP) antibodies, anticardiolipin $\mathrm{IgG} / \mathrm{IgM}$, and anti-2 glycoprotein $\operatorname{IgG} / \mathrm{IgM}$ - all within the normal range.

The patient is currently 29 years old, has a good musculoskeletal constitution, and has been a non-smoker since 2016. He smoked for nearly 10 years, 20 cigarettes per day, and consumed alcohol until January 2020, with excessive drinking 1-2 times/week.

Given our current knowledge and the specifics of the case, we were interested in the patient's previous medical documentation and discovered that the patient's medical issues began at the age of 21 years (October 2013), when he first reported pain along the right leg, followed by coughing, fatigue, and increased sweating. After 10 days of antibiotic, analgesic, and rest, the complaints had completely resolved. A year later, similar symptoms appeared (August 2014). Chest pain and dyspnea also occur at this time. Laboratory tests, chest X-rays, and ECGs were performed. Antibiotic and symptomatic therapy was used to treat the symptoms again. Anamnestic, the patient reported one episode of the same symptoms a few months later, at the end of 2014. This time, the presence of fresh blood in the cough is accompanied by chest pain, coughing, and dyspnea. He did not seek medical attention because he was temporarily working abroad. After 2 weeks, the symptoms resolved on their own.

\section{DISCUSSION}

We presented the case of a male patient with recurrent VTE whose first VTE episode manifested at age of 21, based on anamnestic data. Eight years after the first symptom, four hospitalizations and three PTEs confirmed by CT, genotyping revealed the presence of a homozygous FVL mutation.
The annual incidence of VTE in FVL patients is $0.5 \%(9,10)$. Carriers of FVL have a significantly higher risk of recurrent thromboembolic events than patients without this abnormality $(11,12)$. The relative risk for PTE in individuals with FVL is approximately 3 -fold, while the risk for DVT is approximately 7-fold in FVL carriers (13). The risk of VTE increases 3-8 times in heterozygous carriers of the mutation, and 50-80 times in homozygous carriers (14). The sequence of events in our patient corresponds to the data in the cited literature.

The risk of VTE in carriers of the FVL mutation is 3-5 times higher in patients with a positive family history of VTE before the age of 50, and 13 times higher in those with more than 1 affected family member (15). The FVL mutation alone does not increase the risk of arterial thrombosis, that is, heart attack and stroke (16-18). Our patient's parents had an ischemic stroke when they were 60 , but no other thromboembolic events were documented by them or other relatives. Furthermore, parents and relatives were not genetically tested. The limitations of this case are reflected in the late recognized genetic predisposition, which could be a result of a lack of diagnostics and uniform protocols in our health-care facilities.

In the line with our patient's psoriasis and FVL mutation, our patient may be at an increased risk of a VTE event. Patients with mild-to-moderate psoriasis may have an increased risk of VTE events because chronic systemic inflammation leads to increased hypercoagulability $(19,20)$. These two causes of hypercoagulability are rare together, and only a few cases have been described (19-21).

We were intrigued by the fact that we could not find any information about D-dimer levels in the medical records for any of the hospitalizations. Assuming that the cause is technical, the $\mathrm{D}$-dimer level was measured once during the first hospitalization and monitored again during the fourth hospitalization. D-dimer concentration correlates with disease severity in patients with a confirmed diagnosis of VTE and can be used to predict an adverse outcome $(22,23)$. Furthermore, increased D-dimer levels were associated with significantly higher hazard ratio of recurrence (22). We could not compare this due to lack of analysis.

According to the findings of the cohort study, $47 \%$ of the first thrombotic events occurred in patients who did not have clinical or surgical conditions that predisposed to thrombosis. Recurrent thromboembolism occurred at a rate of 59\%, with $90 \%$ of recurrent events occurring when patients were not receiving anticoagulation therapy (24). We also concluded that our patient experienced thromboembolic events while not on anticoagulant therapy. We want to emphasize that the patient stopped taking the medication on his own accord.

The initial management of VTE caused by the FVL mutation is no different than that of any other patient with a thrombus; the duration of treatment is determined by the risk factors. Following a first event, some authors recommend 6 months of anticoagulant therapy (25). However, in some conditions, long-term anticoagulant therapy should be considered. People who are homozygous for this mutation should be considered for long-term anticoagulant therapy after closely examining the risks and benefits $(19,25-27)$. Several studies have shown that direct thrombin inhibitors (dabigatran, argatroban, and bivalirudin) (28) and DOACs 
(rivaroxaban and apixaban) $(29,30)$ are effective for VTE caused by FVL mutation. Aside from anticoagulant therapy, these patients are advised to reduce risk factors, regularly control coagulation status, as well as to educate them about their disease. It is crucial to recognize early symptoms and seek medical attention (7).

\section{CONCLUSION}

This is a case of a young man with homozygous FVL and a few other risk factors who suffered from repeated VTE over several years. The disease manifested as PTE 3 times and was preceded by DVT of the lower extremities twice. Thrombophlebitis of the left leg occurred only once, with no evidence of PTE and no additional diagnostics.

Repeated VTE requires a more detailed determination of the predisposing factors and etiology when manifested at a younger age without significant risk factors. Analyzing this case, we conclude that the complexity of the health-care system, as well as the COVID-19 pandemic, slowed the earlier confirmation of the FVL mutation. Cases with homozygous FVL are known to have repeated VTE events, and therefore, they should be properly diagnosed and managed on their first VTE event, work on preventing recurrent VTE through better patient education, emphasizing the importance of regular therapy, and improving quality of life. This should save patients a lot of suffering as well as save the health system a lot of costs wasted on repeatedly treating these patients.

\section{REFERENCES}

1. Palareti G. Recurrent venous thromboembolism: What is the risk and how to prevent it. Scientifica 2012;2012:391734. https://doi.org/10.6064/2012/391734

2. Juul K, Tybjærg-Hansen A, Mortensen J, Lange P, Vestbo J, Nordestgaard BG. Factor $\checkmark$ leiden homozygosity, dyspnea, and reduced pulmonary function. Arch Intern Med 2005;165(17):2032-6.

https://doi.org/10.1001/archinte.165.17.2032.

3. Bertina RM, Koeleman BP, Koster T, Rosendaal FR, Dirven RJ, de Ronde H, et al. Mutation in blood coagulation factor $\mathrm{V}$ associated with resistance to activated protein C. Nature 1994;369(6475):64-7.

https://doi.org/10.1038/369064a0

4. Dahlbäck B. New molecular insights into the genetics of thrombophilia. Resistance to activated protein $\mathrm{C}$ caused by Arg506 to Gin mutation in factor $\mathrm{V}$ as a pathogenic risk factor for venous thrombosis. Thromb Haemostasis 1995;74(7):139-48. https://doi.org/10.1055/s-0038-1642667.

5. Ridker PM, Miletich JP, Hennekens $\mathrm{CH}$, Buring JE. Ethnic distribution of factor V Leiden in 4047 men and women: Implications for venous thromboembolism screening. JAMA 1997;277(16):1305-7. https://doi.org/10.1001/jama.1997.03540400055031.

6. Rosendaal FR, Koster T, Vandenbroucke JP, Reitsma PH. High risk of thrombosis in patients homozygous for factor $\mathrm{V}$ Leiden (activated protein $\mathrm{C}$ resistance). Blood 1995;85:1504-8. https://doi.org/10.1182/blood.v85.6.1504.bloodjournal8561504.

7. Shaheen K, Alraies MC, Alraiyes AH, Christie R. Factor V Leiden: How great is the risk of venous thromboembolism. Cleve Clin J Med 2012;79(4):265-72. https://doi.org/10.3949/ccjm.79a.11072.

8. Nicholson M, Chan N, Bhagirath V, Ginsberg J. Prevention of venous thromboembolism in 2020 and beyond. J Clin Med 2020;9(8):2467. https://doi.org/10.3390/jcm9082467.

9. Stolz E, Kemkes-Matthes B, Pötzsch B, Hahn M, Kraus J, Wirbartz A, et al. Screening for thrombophilic risk factors among 25 German patients with cerebral venous thrombosis. Acta Neurol Scand 2000;102:31-6. https://doi.org/10.1034/j.1600-0404.2000.102001031.x.

10. Langlois NJ, Wells PS. Risk of venous thromboembolism in relatives of symptomatic probands with thrombophilia: A systematic review. Thromb Haemost 2003;90:17-26. https://doi.org/10.1055/s-0037-1613594.

11. Kyrle PA, Rosendaal FR, Eichinger S. Risk assessment for recurrent venous thrombosis. Lancet 2010;376(9757):2032-9.

https://doi.org/10.1016/s0140-6736(10)60962-2.

12. Al-Mondhiry HA, Nifong TP, Eyster ME. The phenotypic expression of homozygous and compound heterozygous factor V R506Q (factor V Leiden, FVL) and factor II A20210G: Ten years experience at a referral center. Blood 2011;118(21):5252. https://doi.org/10.1182/blood.v118.21.5252.5252.

13. Strouse JJ, Tamma P, Kickler TS, Takemoto CM. D-dimer for the diagnosis of venous thromboembolism in children. Am J Hematol 2009;84(1):62.

https://doi.org/10.1002/ajh.21311.

14. Rosendaal FR. Venous thrombosis: The role of genes, environment, and behavior. Hematology Am Soc Hematol Educ Program 2005;2005(1):1-2.

15. Bezemer ID, van der Meer FJ, Eikenboom JC, Rosendaal FR, Doggen CJ. The value of family history as a risk indicator for venous thrombosis. Arch Intern Med 2009;169(6):610-5.

https://doi.org/10.1001/archinternmed.2008.589.

16. Arsov T, Miladinova D, Spiroski M. Factor $V$ Leiden is associated with higher risk of deep venous thrombosis of large blood vessels. Croat Med J 2006;47:433-9.

17. Simioni P, Prandoni P, Lensing AW, Manfrin D, Tormene D, Gavasso S, et al. Risk for subsequent venous thromboembolic complications in carriers of the prothrombin or the factor $\mathrm{V}$ gene mutation with a first episode of deep-vein thrombosis. Blood J Am Soc Hematol 2000;96(10):3329-33.

https://doi.org/10.1182/blood.v96.10.3329.h8003329a_3329_3333.

18. Ornstein DL, Cushman M. Cardiology patient page. Factor V Leiden. Circulation 2003;107:e94-7.

19. Lutsey PL, Prizment AE, Folsom AR. Psoriasis is associated with a greater risk of incident venous thromboembolism: The lowa Women's health study. J Thromb Haemost 2012;10(4):708-11.

https://doi.org/10.1111/j.1538-7836.2012.04646.x.

20. Ungprasert $P$, Sanguankeo $A$, Upala $S$, Suksaranjit $P$. Psoriasis and risk of venous thromboembolism: A systematic review and meta-analysis. QJM 2014;107(10):793-7. https://doi.org/10.1093/qjmed/hcu073.

21. Baloski M, llievska DB, Brishkovska-Boshkovski V, Hasan T, et al. Deep vein thrombosis and recurent pulmonary embolism in a patient with thrombophilic mutations and generalized psoriasis: A case report. Sanamed 2020;15(2):183-8. https://doi.org/10.24125/sanamed.v15i2.391.

22. Arnautović-Torlak V, Pojskić B, Žutic H, Rama A. Values of D-dimer test in the diagnostics of pulmonary embolism. Med Glasnik 2014;11(2):258-63.

23. Topić RZ, Krleža JL. D-dimer: Kako pravilno tumačiti nalaz. Paediatr Croatica 2016;60(4):161-5

24. Federici $\mathrm{EH}, \mathrm{Al}-\mathrm{Mondhiry} \mathrm{H}$. High risk of thrombosis recurrence in patients with homozygous and compound heterozygous factor V R506Q (Factor V Leiden) and prothrombin G20210A. Thromb Res 2019;182:75-8. https://doi.org/10.1016/j.thromres.2019.07.030.

25. Baglin T, Gray E, Greaves M, Hunt BJ, Keeling D, Machin S, et al. Clinical guidelines for testing for heritable thrombophilia. Br J Haematol 2010;149:209-20. https://doi.org/10.1111/j.1365-2141.2009.08022.x

26. Press RD, Bauer KA, Kujovich JL, Heit JA. Clinical utility of factor V Leiden (R506Q) testing for the diagnosis and management of thromboembolic disorders. Arch Pathol Lab Med 2002;126:1304-18. https://doi.org/10.5858/2002-126-1304-cuofvl

27. Palareti G, Legnani C, Cosmi B, Valdré L, Lunghi B, Bernardi F, et al. Predictive value of $D$-dimer test for recurrent venous thromboembolism after anticoagulation withdrawal in subjects with a previous idiopathic event and in carriers of congenital thrombophilia. Circulation 2003;108(3):313-8. https://doi.org/10.1161/01.cir.0000079162.69615.0f

28. Van Cott EM, Khor B, Zehnder JL. Factor V Leiden. Am J Hematol 2016;91:46-9.

29. Cook RM, Rondina MT, Horton DJ. Rivaroxaban for the long-term treatment of spontaneous ovarian vein thrombosis caused by factor $\mathrm{V}$ Leiden homozygosity. Ann Pharmacother 2014;48:1055-60. https://doi.org/10.1177/1060028014533304.

30. Sueta D, Ito M, Uchiba M, Sakamoto K, Yamamoto E, Izumiya Y, et al. A case of pulmonary thromboembolism due to coagulation factor $\mathrm{V}$ Leiden in Japan usefulness of next generation sequencing. Thromb J 2017;15(1):1-4

https://doi.org/10.1186/s12959-017-0132-6. 